\title{
Dyeability and Mechanical Properties of Acrylonitrile-Diallylamine Salts Copolymers
}

\author{
${ }^{1}$ Abir S. Abdel-Naby and ${ }^{2}$ Salha N. Al-Harthi \\ ${ }^{1}$ Department of Chemistry, Faculty of Science, Fayium University, Fayium, Egypt \\ ${ }^{2}$ Department of Chemistry, Faculty of Science, College of Girls, Dammam University, Dammam, Saudi Arabia
}

Received 2012-11-11, Revised 2013-03-26; Accepted 2013-05-31

\begin{abstract}
The dyeability of Acrylonitrile-Diallylamine Acetate (AN-DAA acetate) and Acrylonitrile-Diallylguanidine Acetate (AN-DAGA) copolymers have been studied with both conventional and ultrasonic methods. The results obtained were compared to the parent polyacrylonitrile. The effect of dye concentration, dye bath $\mathrm{pH}$, dyeing time and temperature were studied and the results obtained by dyeing with both techniques were compared. Color strength values were found to be higher with ultrasonic than with conventional method. To identify the structural changes in the dyed copolymers as compared to dyed PAN, during thermal treatment at high temperature, XRD analysis were performed. The XRD patterns of all heated dyed copolymers are similar to the corresponding unheated samples while that of the heated dyed PAN changed dramatically. The mechanical properties of the dyed copolymers had been also studied and compared to those of the dyed PAN.
\end{abstract}

Keywords: Acrylonitrile, Diallylamine Salts, Copolymerization, Mechanical Properties, Dyeability

\section{INTRODUCTION}

Acrylonitrile based copolymers have a variety of applications in textile industry. Polyacrylonitrile because of their high melting point, high melt viscosity and poor thermal stability have few application (Abdel-Naby, 2011). Polyacrylonitrile is prepared by addition polymerization of acrylonitrile (Zhou et al., 2011). The pure homopolymer suffers from poor heat stability at high temperature as well as it possesses low dyeability.

Copolymerization of acrylonitrile with suitable comonomers gave the polymer its extra thermal stability and also improved its dyeability (Abdel-Naby and Aboubshait, 2013; Tsai and Lin, 1990; Bahrami et al., 2003; Abdel-Naby, 2011; 2012). Copolymerization of acrylonitrile with acrylic acid in DMF-water matrix showed high thermal stability (Moghadam and Bahrami 2005). Moreover, acrylonitrile copolymers with vinyl acetate or methyl acrylate are used for fiber production in textile industries (Sanderson, 2004).

In our previous work (Abdel-Naby and Al-Harthi, 2013) the copolymerization of acrylonitrile with diallylamine salts led to thermal stable copolymers as shown from their DSC thermograms and their thermal gravimetric analysis.

The aim of the present work is to investigate the dyeability of the acrylonitrile-diallylamine salts copolymers as compared to PAN homopolymer.

\section{MATERIALS AND METHODS}

\subsection{Experimental}

\subsubsection{Materials}

Acrylonitrile (AN) from (Acros organic). Diallylamine (DAA) 97\% from (Acros organic). Cyanamide 95\% from (Acros organic). Acetonitrile from (Acros organic). Sodium bisulfate from (Acros organic). Potassium persulphate 99\% from (Acros organic). Glacial Acetic Acid (GAA) from (Acros organic). Methanol from (Aldrich). 1-Butanol from (Acros organic). Acetone from (Aldrich). Dimethyl Formamide (DMF) from (Acros organic). The coloring substance (C.I. Arston Basic Red 5BL 200\%) was supplied by Dystar Company, Cairo, Egypt. The dye chemical name Corresponding Author: Abir S. Abdel-Naby, Department of Chemistry, Faculty of Science, Fayium University, Fayium, Egypt 
is [2-[[4-[(2-cyano-4-nitrophenyl) azo $]$ phenyl $]$ ethylamino] ethyl] triethyl ammonium methyl sulphate.

\subsection{Apparatus}

A crest ultrasonic, TRU-SWEEPTM ultrasonic bench top cleaner bath, model $575 \mathrm{D}$ with a capacity $5.75 \mathrm{~L}$, was used.

\subsection{Synthesis of Diallylamine Salts}

Diallylaminesalts were synthesized according to the method described by (Zaikov et al., 2004).

Step 1: Formation of diallylamine acetate.

Glacial acetic acid $(1.00 \mathrm{~mol})$ was added with stirring to cooled DAA $(1.05 \mathrm{~mol})$ in a one-neck flask $(0.5 \mathrm{~L})$ and diallylamine acetate was obtained (Fig. 1).

Step 2: Formation of diallylguanidine acetate.

To obtain the diallylguanidine acetate, a cyanamide $(1.00 \mathrm{~mol})$ in acetonitrile $\left(\sim 60 \mathrm{~mL}^{-1}\right)$ was added to the resulting diallylamine acetate.After this reaction mixture was stirred (for about $10 \mathrm{~min}$ ) without cooling. The prepared mixture was added dropwise to reflux acetonitrile $\left(25-250 \mathrm{~mL}^{-1}\right)$ in a three-neck flask $(1.00 \mathrm{~L})$ with a reflux condenser and dropping funnel over a period of about $1 \mathrm{~h} 40 \mathrm{~min}$ (crystalline product appeared after addition of half of the mixture), then this mixture was refluxed an additional nearly $1 \mathrm{~h} 40 \mathrm{~min}$. The precipitate was filtered off, washed many times with

acetonitrile, n-butanol and acetone and dried in vacuum at about $\left(20^{\circ} \mathrm{C}\right)$ to give DAGA (m.p. $\left.212-214^{\circ} \mathrm{C}\right)$ (Fig. 2).

\subsection{Copolymerization Procedure}

\subsubsection{Copolymerization of Acrylonitrile with Diallylamine Acetate}

To the diallylamine acetate prepared in three-neck flask acrylonitrile was added in a given concentration, under nitrogen atmosphere, sodium bisulfate and potassium persulphate were added as radical initiators $(4 \times 10-2) \mathrm{mol} \mathrm{L}^{-1}$, in distilled water. The mixture was refluxed for $(1-2 \mathrm{~h})$ at $\left(45^{\circ} \mathrm{C}\right)$. The precipitated pale yellow copolymer was collected and purified by reprecipitation filtered and washed repeatedly with methanol using soxhlet system. The copolymers compositions were calculated on the basis of their nitrogen and carbon-hydrogen contents (Abdel-Naby and Al-Harthi, 2013). Table 1 and 2 shows the found copolymer compositions of each sample.

\subsection{Copolymerization of Acrylonitrile with Diallylguanidine Acetate}

Polymerization ampoules of pyrex glass were charged with monomer, water and the initiator sodium bisulfate and potassium persulphate were added as radical initiators $\left(4 \times 10^{-2}\right) \mathrm{mol} \mathrm{L}^{-1}$. The ampoules were covered with serum caps, cooled and purged with a slow stream of purified nitrogen.

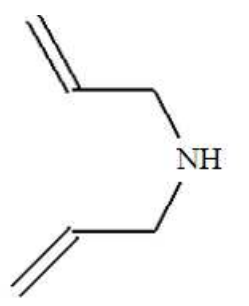

$\mathrm{CH}_{3} \mathrm{COOH}$

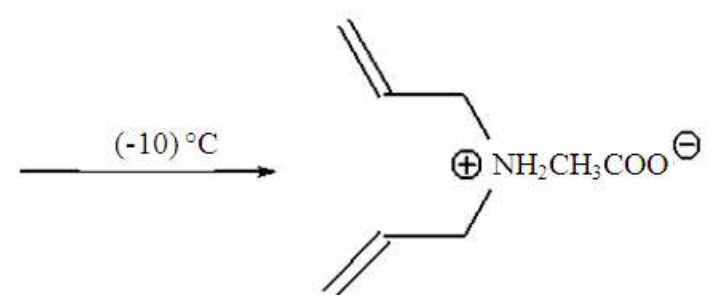

Fig. 1. Synthesis of diallylamine acetate
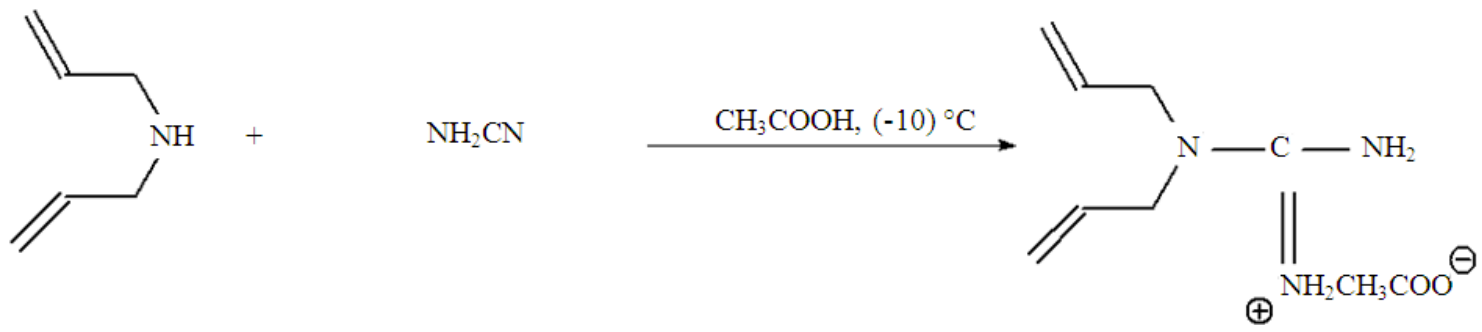

Fig. 2. Synthesis of diallylguanidine acetate 
Table 1. The samples compositions data (found) for (AN-DAA acetate) copolymers

\begin{tabular}{llll}
\hline & & Copolymer compositions \\
& & - & $\mathrm{M}_{2}$ \\
No & Sample name & $\mathrm{M}_{1}$ & 65 \\
1 & (AN-DAA acetate) & 35 & 40 \\
3 & (AN-DAA acetate) & 60 & 22 \\
\hline
\end{tabular}

Table 2. The samples compositions data (found) for (ANDAGA) copolymers

\begin{tabular}{llll}
\hline & & Copolymer compositions \\
& & - & $\mathrm{M}_{2}$ \\
No & Sample name & $\mathrm{M}_{1}$ & 75 \\
4 & (AN-DAGA) & 25 & 55 \\
5 & (AN-DAGA) & 45 & 45 \\
6 & (AN-DAGA) & 55 & \\
\hline
\end{tabular}

The polymerization was carried out of $\left(50^{\circ} \mathrm{C}\right)$ till the precipitation of the copolymer. The precipitate was then filtered and washed repeatedly with methanol using soxhlet system. The copolymer compositions were calculated on the basis of their nitrogen and carbonhydrogen contents (Abdel-Naby and Al-Harthi, 2013).

\subsection{Dyeing of Acrylonitrile Copolymers using Conventional and Ultrasonic Methods}

$0.5 \mathrm{~g}$ of the prepared copolymer was dyed with a basic dye at liquor ratio of 1: 50 . Dyeing was carried out at $\mathrm{pH}$ values (4-7), temperature $\left(40-80^{\circ} \mathrm{C}\right)$ at time intervals (30-90 min). In case of ultrasonic for comparison, the same conditions of dyeing were carried out using ultrasonic dyeing with power level 300 Watt. Then the dyed samples were rinsed with cold water and washed for $30 \mathrm{~min}$ with warm distilled water $\left(50^{\circ} \mathrm{C}\right)$ and dried.

\subsection{Mesurements}

\subsubsection{UV/vis Spectroscopy}

UV/visible spectra were obtained using PerkinElmer Lamda $4 \mathrm{UV} / \mathrm{vis}$ spectrophotometer.

\subsection{Quantity of Dye Uptake by AN-Diallylamine Salts Copolymers}

The quantity of dye uptake was estimated using the following Equation 1 (Kamel et al., 2010):

$$
\mathrm{Q}=(\mathrm{Co}-\mathrm{Cf}) \mathrm{V} / \mathrm{W}
$$

where, Q is the quantity of dye-uptake ( $\mathrm{mg} / \mathrm{g}$ ), Co and Cf are the initial and final concentration of the dye solution $\left(\mathrm{mg} \mathrm{L}^{-1}\right)$, respectively. $\mathrm{V}$ is the volume of dye bath/(liter) and $\mathrm{W}$ is the weight of copolymer $(\mathrm{g})$. The concentration of the solution was determined using a calibration of the basic dye.

\subsection{Color Strength}

The color strength of the dyed samples was evaluated by a light reflectance technique using UV/vis spectrophotometer. The relative color strength $(\mathrm{K} / \mathrm{S}$ values) was calculated using the Kubelka-Munk equation (Kamel et al., 2010):

$K / S=(1-R) 2 / 2 R$

Where:

$\mathrm{R}=$ Observed reflectance

$\mathrm{K}=$ Absorption coefficient and

$\mathrm{S}=$ Scattering coefficient

\subsection{X-Ray Diffraction}

X-ray diffraction patterns were recorded using a Rigaku D/max $2500 \mathrm{v} / \mathrm{pc}$ X-ray diffractometer. The diffractograms were measured at $2 \Theta$ in the range of 5$80^{\circ}$ using $\mathrm{Cu} \mathrm{K} \alpha$ as the monochromatic radiation source $(\lambda=1.54 \AA$ Á) by applying a parabolic filter, at a tube voltage of $40 \mathrm{kV}$ and a tube current of $200 \mathrm{~mA}$.

\subsection{Atomic Force Microscope}

The roughness of the polymeric film has been determined using (AA2000 Atomic force microscope).

\subsection{Mechanical Properties}

The tenacity and elongation at break of the dyed copolymer films determined using Instron universal testing machine. The testwere conducted at a laboratory standard environment. The tenacity was determined using the following equation (Khan et al., 2009):

$$
\text { Tenacity }=\frac{\text { Max breaking load }(\mathrm{N})}{\text { Area of the polymeric film }\left(\mathrm{nm}^{2}\right)}
$$

\subsection{Ultraviolet Fastness of the Dyed Samples}

The UV fastness of various dyed samples was performed using low pressure mercury lamp $(\lambda=250 \mathrm{~nm})$.

\section{RESULTS AND DISCUSSION}

\subsection{Characterization of Monomers}

The DAGA and DAA acetate comonomers were prepared according to the method previously described. 
Abir S. Abdel-Naby and Salha N. Al-Harthi / American Journal of Applied Sciences 10 (5): 525-535, 2013

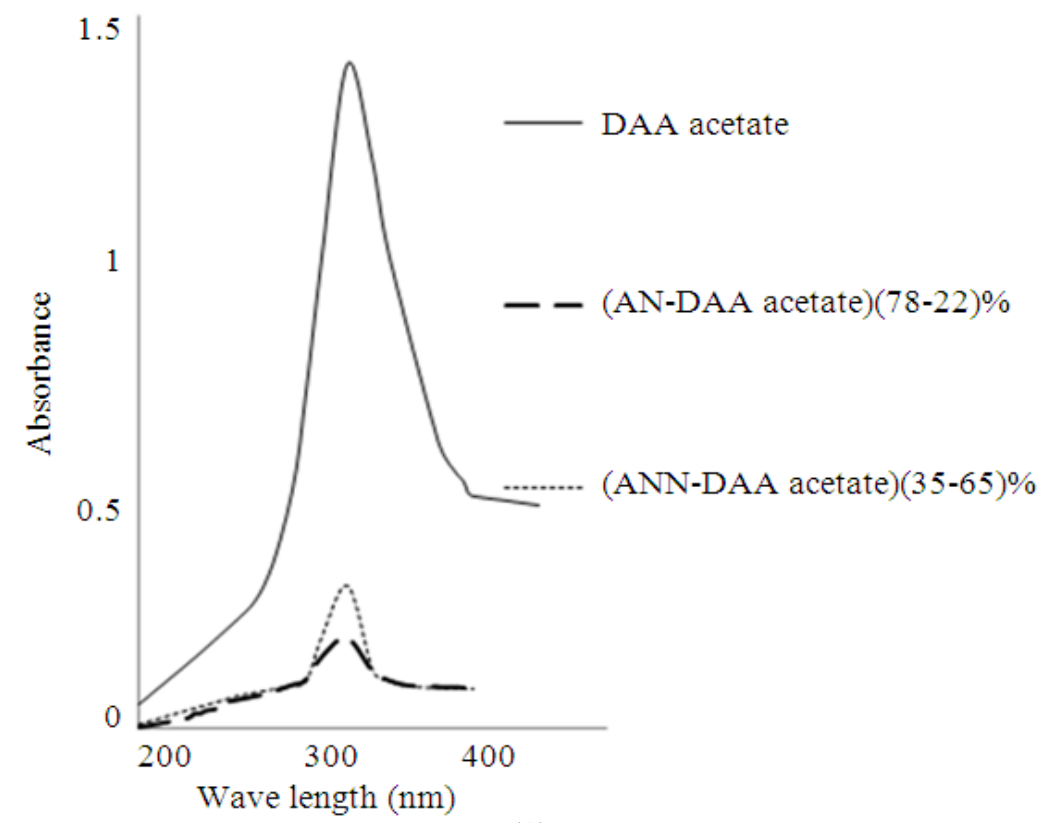

(A)

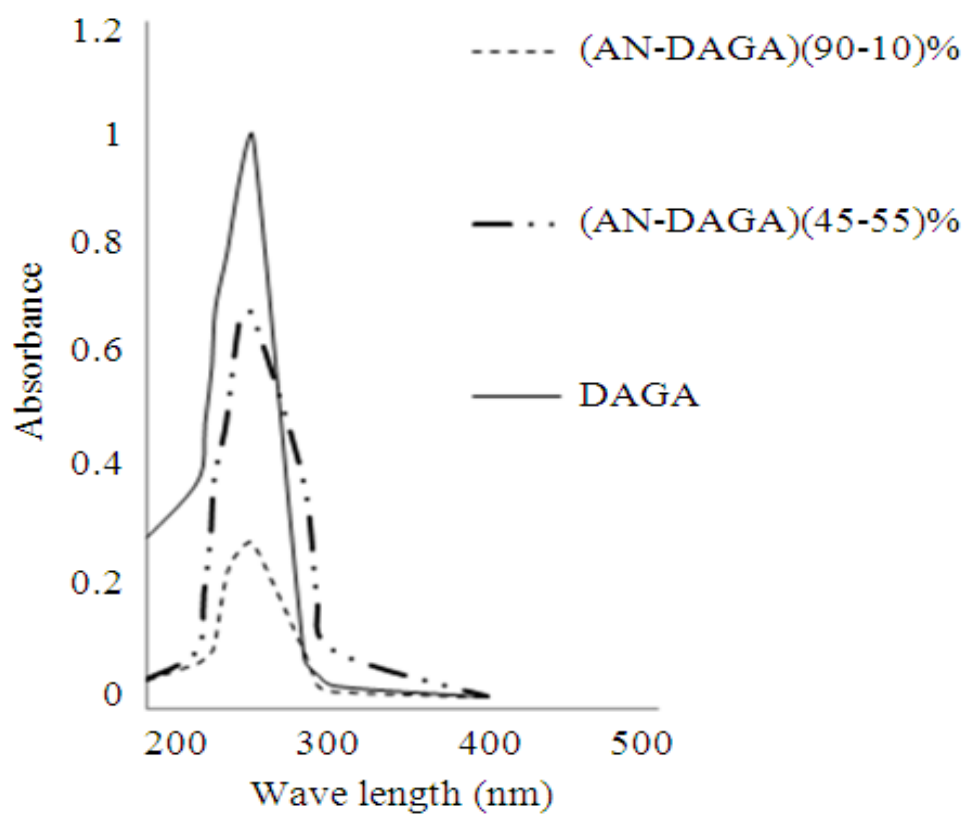

(B)

Fig. 3. UV/vis spectra of DAA acetate and its copolymers (A) and DAGA and its copolymers (B)

We had previously confirmed (Abdel-Naby and AlHarthi, 2013) the structure of the two comonomers as well as the structure of the AN/DAGA and AN/DAA acetate copolymers using FTIR spectroscopy.
Investigation of the prepared copolymer samples in DMF by UV spectrophotometry are shown in (Fig. 3).

Figure $\mathbf{3 A}$ illustrates the UV spectra of various compositions of AN-DAA acetate copolymers. 


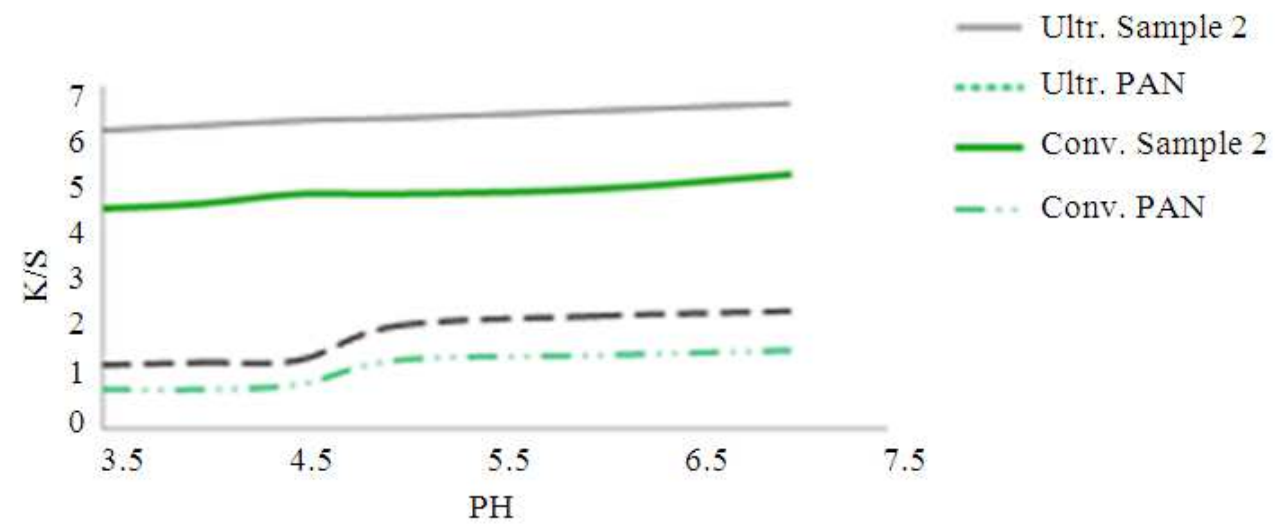

(A)

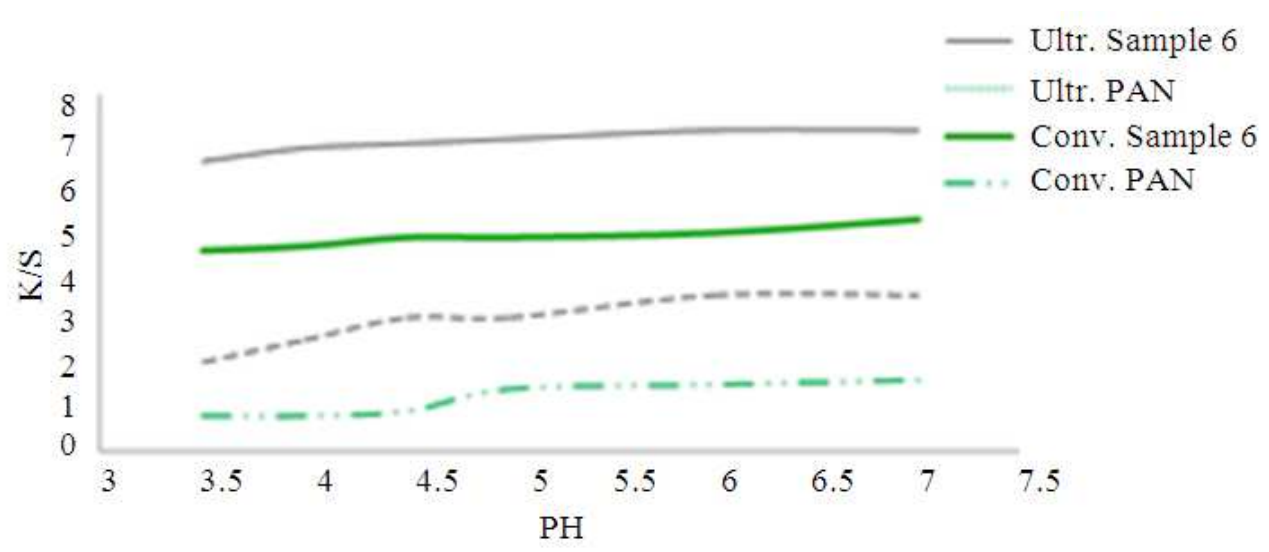

(B)

Fig. 4. Effect of dye $\mathrm{pH}$ on the color strength of the AN-DAA acetate (A) and AN-DAGA (B) copolymer using C.I. Astrazon Basic Red 5BL $200 \%$ as compared to PAN. Dyeing conditions: copolymer 0.5 g, L.R. $1: 50$, dye conc. $0.5 \%$, at $80{ }^{\circ} \mathrm{C}$ for $45 \mathrm{~min}$ in case of conventional and ultrasonic methods

A broad peak at $320 \mathrm{~nm}$ indicating the presence of the diallylamine acetate in the PAN backbone. Moreover, Fig. 3B, which illustrates the UV spectra of various compositions of AN-DAGA copolymers, shows strong peak at $260 \mathrm{~nm}$ indicating the presence of DAGA moieties in the PAN matrix.

\subsection{Dyeing of AN-DAGA and AN-DAA Acetate Copolymers}

The dyeability of Acrylonitrile-Diallylamine Acetate (AN-DAA acetate) and Acrylonitrile-Diallylguanidine Acetate (AN-DAGA) copolymers was studied with both Conventional (CT) and Ultrasonic (US) methods. Table 3 shows the quantity of the dye up take by each copolymer sample, according to Equation 1.

\subsection{Factors Affecting Dyeing Process}

In order to study the factors affecting the dyeability of the two AN/ DAA salts copolymers as compared to PAN. Sample 2 (AN-DAA acetate) $(60: 40) \%$ and sample 6 (AN-DAGA) $(55: 45) \%$ had been chosen for the study as they possess comparable copolymer composition ratios.

\subsection{Effect of pH}

Figure 4 shows the color strength (K/S) (Equation 2) for dyed samples using both Conventional (CT) and Ultrasonic (US) methods. It can be seen that the color strength $(\mathrm{K} / \mathrm{S})$ exhibits little gradual increasing with the increase of the $\mathrm{pH}$ of the dyeing bath from $\mathrm{pH} 4$ to $\mathrm{pH} 7$ irrespective of the method of dyeing, but with a slightly improvement in the dyeability in case of the ultrasonic dyeing process. 
Abir S. Abdel-Naby and Salha N. Al-Harthi / American Journal of Applied Sciences 10 (5): 525-535, 2013

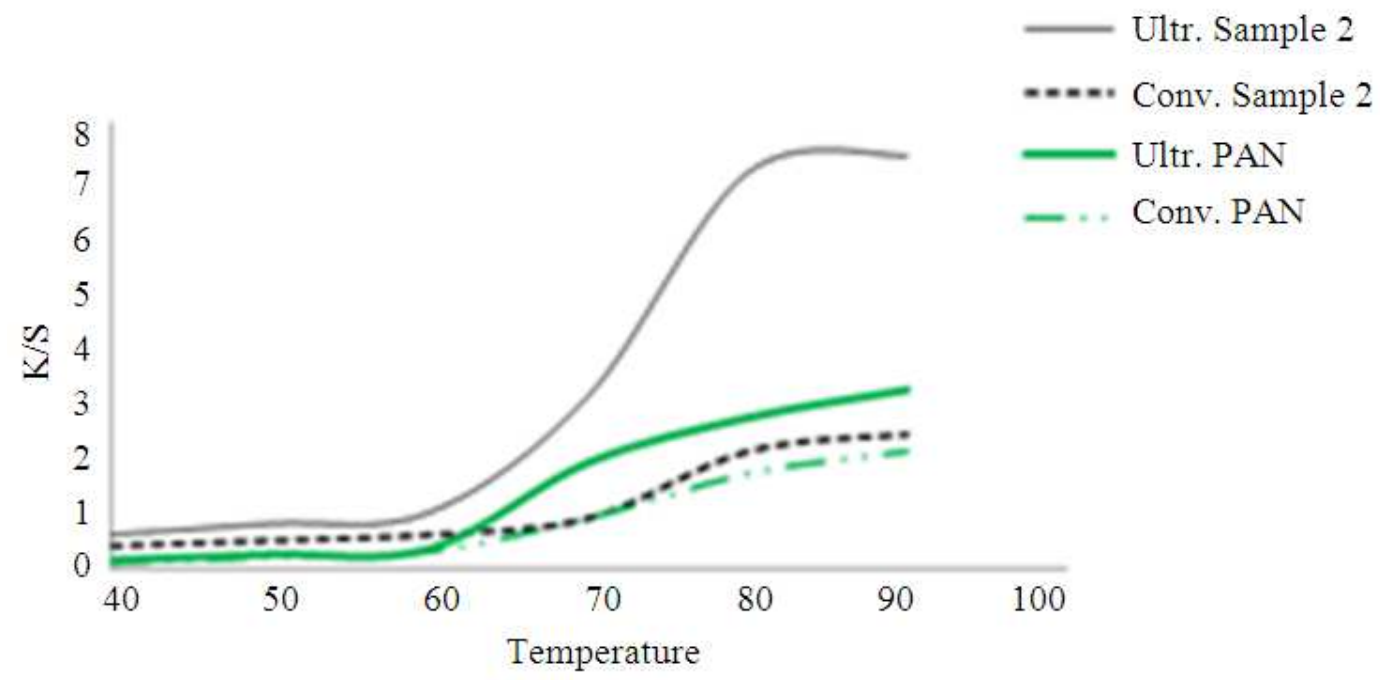

(A)

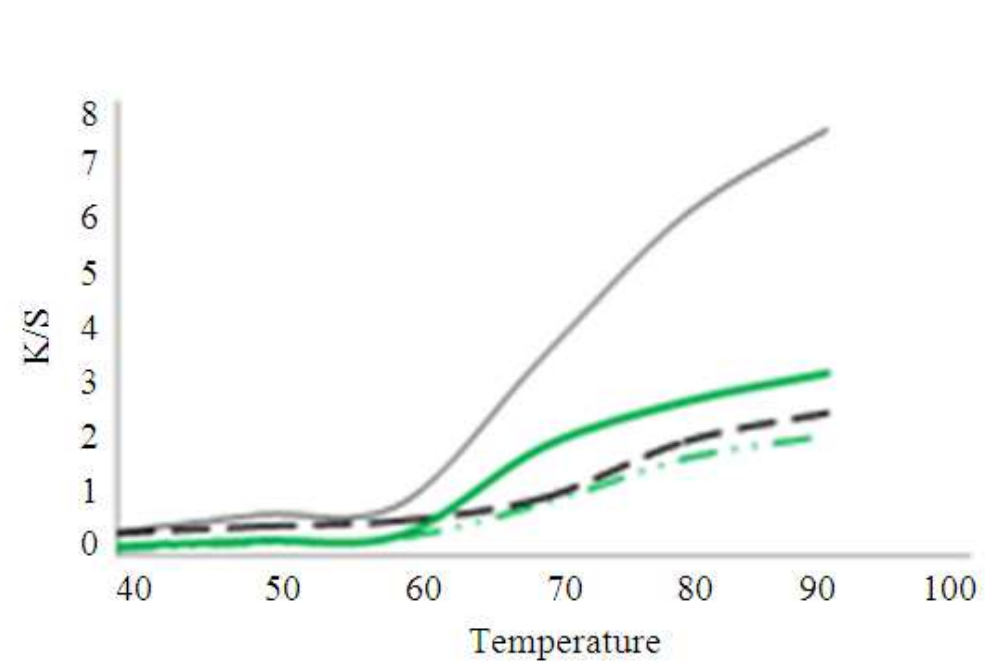

Ultr. Sample 6

.... Conv. Sample 6

Ultr. PAN

-... Conv. PAN

(B)

Fig. 5. Effect of temperature on the color strength of the dyed AN-DAA acetate (A) and AN-DAGA (B) copolymer using C.I. Astrazon Basic Red 5BL 200\% as compared to PAN. Dyeing conditions: copolymer 0.5 g, L.R. 1:50, dye conc. $0.5 \%$, pH 7 for $45 \mathrm{~min}$ in $\mathrm{c}$

Table 3. The quantity of dye up take of AN/ DAA salts copolymers compared to PAN

\begin{tabular}{lllll}
\hline Sample code & Sample name & Sample compositions \% & $\begin{array}{l}\text { Q }(\mathrm{mg} / \mathrm{g}) \text { using } \\
\text { ultrasonic method }\end{array}$ & $\begin{array}{l}\text { Q (mg/g) using } \\
\text { conventional method }\end{array}$ \\
\hline 1 & (AN-DAA acetate) & $35: 65$ & 65.0 & 54.0 \\
2 & (AN-DAA acetate) & $60: 40$ & 50.0 & 36.0 \\
3 & (AN-DAA acetate) & $78: 22$ & 26.0 & 19.0 \\
4 & (AN-DAGA) & $25: 75$ & 96.0 & 85.0 \\
5 & (AN-DAGA) & $45: 55$ & 55.0 & 44.0 \\
6 & (AN-DAGA) & $55: 45$ & 47.0 & 37.0 \\
- & PAN & 100 & 5.2 & 2.5 \\
\hline
\end{tabular}


Abir S. Abdel-Naby and Salha N. Al-Harthi / American Journal of Applied Sciences 10 (5): 525-535, 2013

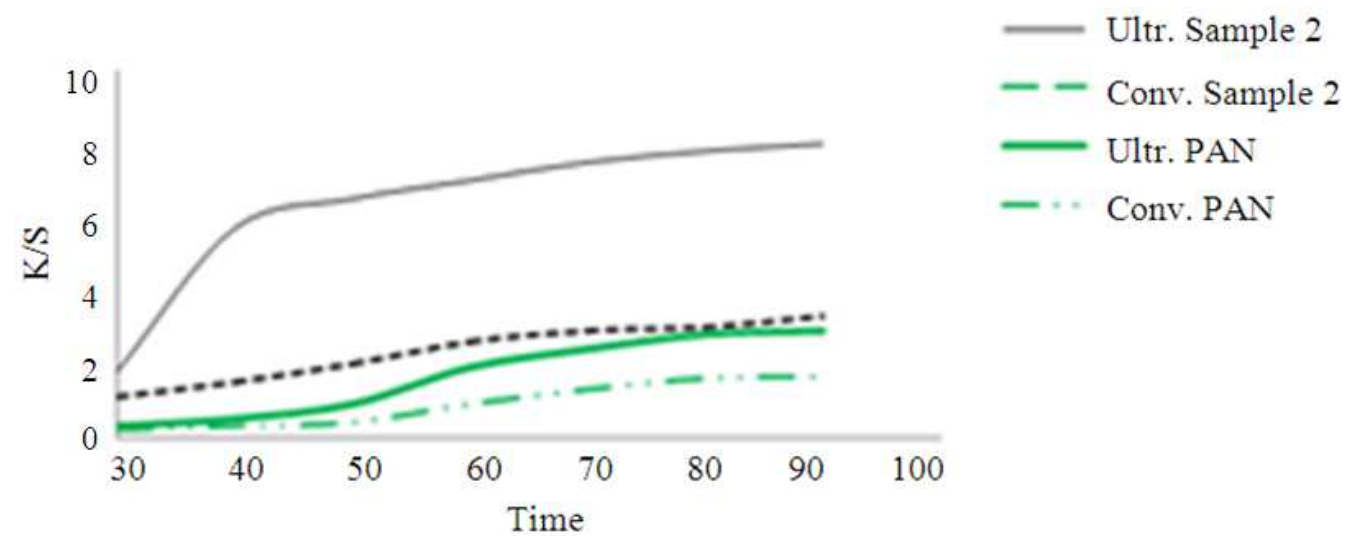

(A)

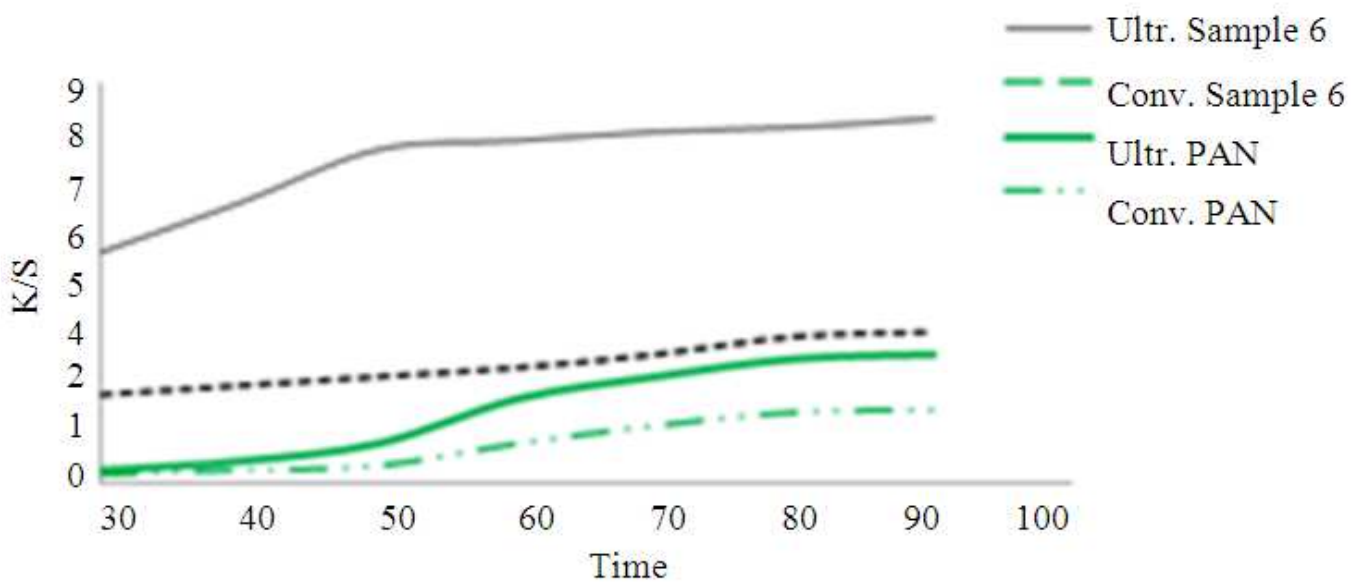

(B)

Fig. 6. Effect of time on the color strength of the dyed AN-DAA acetate (A) and AN-DAGA (B) copolymer using C.I. Astrazon Basic Red 5BL $200 \%$ as compared to PAN. Dyeing conditions: copolymer 0.5 g, L.R. $1: 50$, dye conc. $0.5 \%$, pH 7 , at $80^{\circ} \mathrm{C}$ in case of conventional and ultrasonic methods

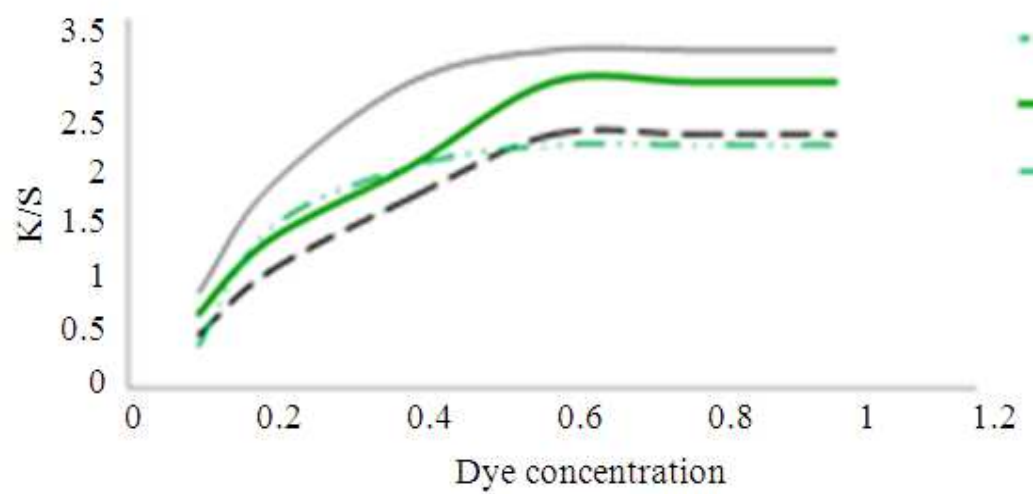

Ultr. Sample 2

..... Ultr. PAN

Conv. Sample 2

-... Conv. PAN

(A) 


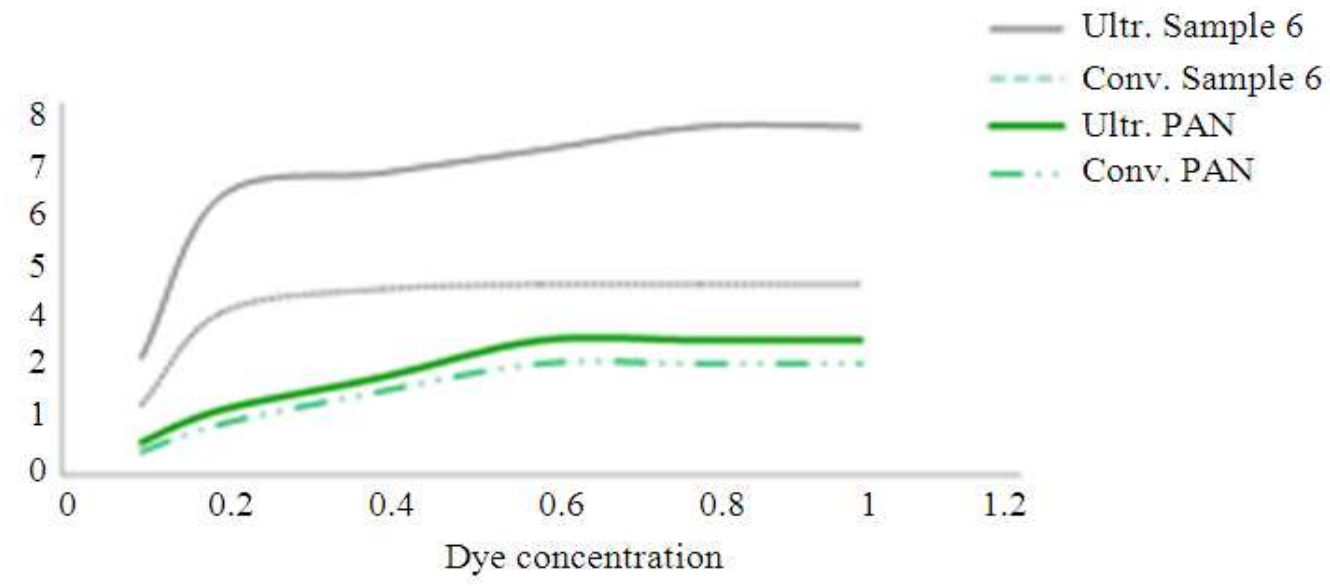

(B)

Fig. 7. Effect of dye conc. g/l on the color strength of the dyed AN-DAA acetate (A) and AN-DAGA (B) copolymer usingC.I. Astrazon Basic Red 5BL 200\% as compared to PAN. Dyeing conditions: copolymer 0.5 g, L.R. 1:50using pH 4.5, at $80{ }^{\circ} \mathrm{C}$ for $45 \mathrm{~min}$ in case of conventional and ultrasonic methods

\subsection{Effect of Temperature}

The effect of dye temperature on the dyeability of AN-DAA salt copolymers was shown in Fig. 5. It is clear that the color strength $(\mathrm{K} / \mathrm{S})$ value increases with the increase in the dyeing temperature in both the US and CT methods with a more pronounced increase in the second case than the first one. Generally, in case of the US dyeing method, the $\mathrm{K} / \mathrm{S}$ values increase as the temperature increases from 40 to $80^{\circ} \mathrm{C}$. This result may be due to the fact that high temperature enhances the copolymer swelling as well as that it enhances the dye diffusion. Also, the US power provides other additional factor of de-aggregation of the dye molecules.

\subsection{Effect of Time}

The effect of dyeing time was studied under US and CT conditions for different dyeing time $(30-90 \mathrm{~min})$ to reveal the effect of power ultrasonic on the dyeability of the AN/DAA salts copolymers dyed with C.I. Astrazon Basic Red 5BL dye. As shown in Fig. 6, the color strength obtained was increased as the time increased for both US and CT methods, with a much higher colorstrength value at all points in the US case.

\subsection{Effect of Dye Concentration}

Figure 7 shows the effect of dye concentration on the dyeing process using ultrasonic method as well as CT method, of the AN/DAA salts copolymers as compared to PAN. It was found that the $\mathrm{K} / \mathrm{S}$ value always increases with the dye concentration then it levels off because it reaches the equilibrium status. Also, it shows much higher values at all points in US dyeing method as expected. The extra vibration and agitation conferred on the dyeing system upon using the ultrasonic energy method may account for this.

Moreover, for the same dye concentration, the AN/DAGA copolymers (sample 6) exhibits higher $\mathrm{K} / \mathrm{S}$ value than that of AN/DAA acetate copolymers (sample 2).

From all the above mentioned data it is remarkable that dyeability of PAN is highly improved by the introduction of diallylamine moieties into its matrix.

\subsection{X-Ray Diffraction}

To investigate the change in the degree of crystallinity of the dyed AN-DAGA copolymers with various DAGA content during thermal treatment, powder XRD analysis were performed (Fig. 8). Up to $200^{\circ} \mathrm{C}$, the XRD patterns of the heated samples are similar to that of the unheated corresponding copolymers. The XRD pattern of PANcontains two characteristic peaks, strong one at $2 \theta=17^{\circ}$ and weak one at $25^{\circ}$ (Fig. 8A) (Boguslavsky et al., 2005).

When the temperature reaches $300^{\circ} \mathrm{C}$, the dyed PAN sample`s crystal structure changes dramatically (Fig. 8D) while the heated copolymers samples XRD patterns were kept unchanged (Fig. 8B) as compared to those of the corresponding unheated dyed copolymers (Fig. 8C). 
Abir S. Abdel-Naby and Salha N. Al-Harthi / American Journal of Applied Sciences 10 (5): 525-535, 2013

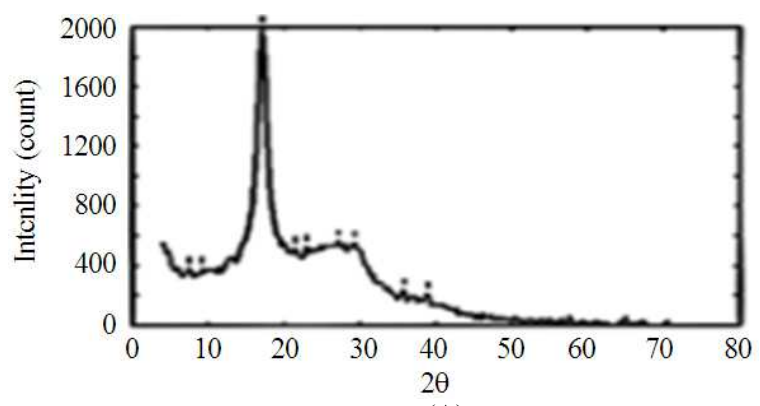

(A)

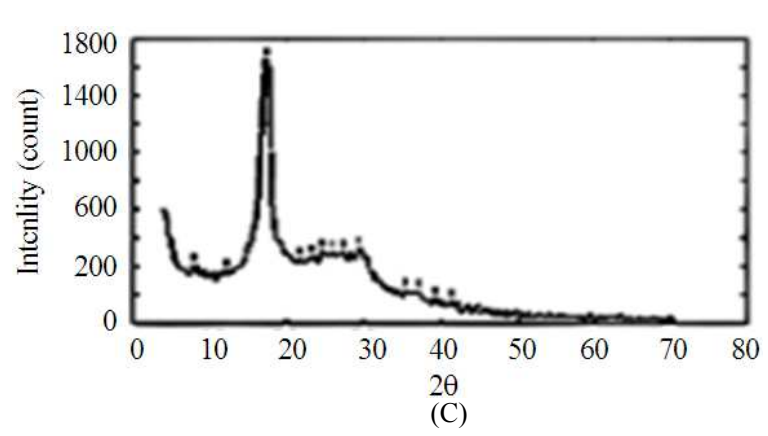

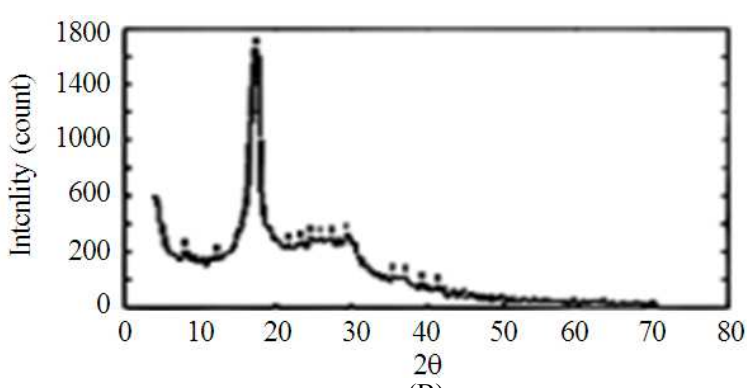

(B)

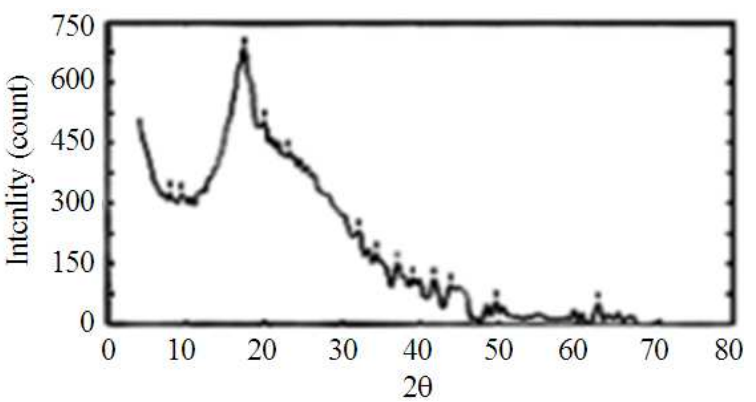

(D)

Fig. 8. Change of XRD patterns with temperature of AN/DAGA as compared to PAN

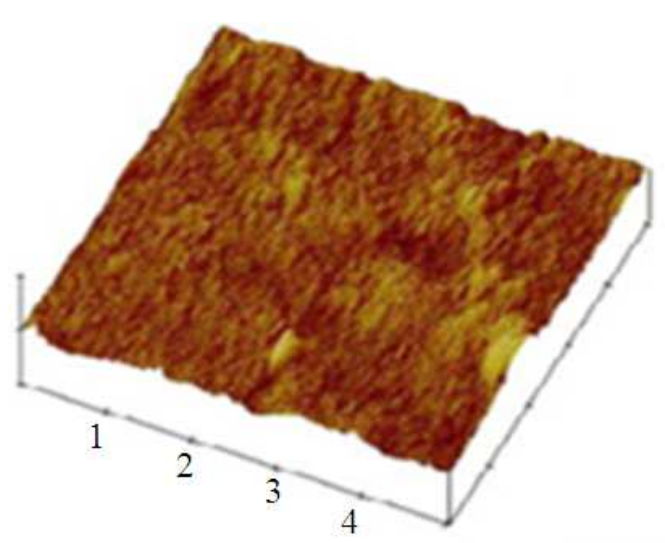

(A)

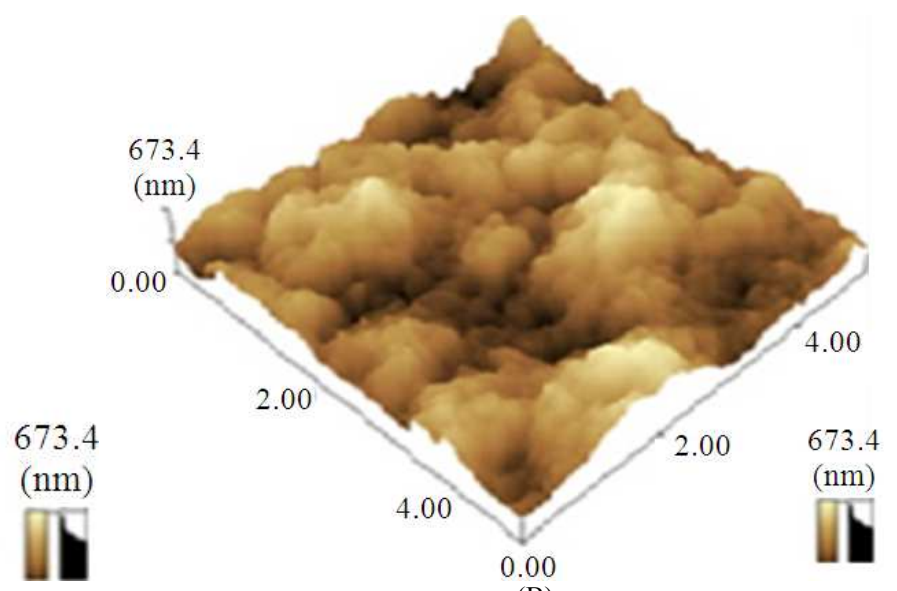

(B)

Fig. 9. Atomic force microscopy topographical images of PAN (A) and (AN-DAGA) copolymer sample 4 (B)

Table 4. Tensile properties of the (AN-DAA acetate) copolymer films compared to PAN

\begin{tabular}{lll}
\hline Film name & $\begin{array}{l}\text { Elastic Young's } \\
\text { modulus }(\mathrm{MPa})\end{array}$ & $\begin{array}{l}\text { Tensile strength } \\
(\mathrm{MPa})\end{array}$ \\
\hline PAN & 1750 & 30 \\
sample 3 & 1100 & 15 \\
sample 2 & 600 & 7 \\
sample 1 & 450 & 4 \\
\hline
\end{tabular}

Table 5. Tensile properties of the (AN-DAGA) copolymer films compared to PAN

\begin{tabular}{llc}
\hline Film name & $\begin{array}{l}\text { Elastic Young's } \\
\text { modulus }(\mathrm{MPa})\end{array}$ & $\begin{array}{l}\text { Tensile strength } \\
(\mathrm{MPa})\end{array}$ \\
\hline PAN & 1750 & 6 \\
sample 6 & 1250 & 9 \\
sample 5 & 800 & 18 \\
sample 4 & 450 & 30 \\
\hline
\end{tabular}


Abir S. Abdel-Naby and Salha N. Al-Harthi / American Journal of Applied Sciences 10 (5): 525-535, 2013

Table 6. Effect of (UV) radiation on the mechanical properties of dyed AN/diallylamine salts copolymers as compared to PAN

\begin{tabular}{|c|c|c|c|c|c|c|}
\hline \multirow[b]{2}{*}{$\begin{array}{l}\text { Exposed } \\
\text { period (h) }\end{array}$} & \multicolumn{2}{|c|}{ (AN-DAA acetate) $(60: 40) \%$} & \multicolumn{2}{|c|}{ AN-DAGA) $(55: 45) \%$} & \multicolumn{2}{|l|}{ PAN } \\
\hline & $\begin{array}{l}\text { Tenacity } \\
\text { strength } \\
\left(\mathrm{N} / \mathrm{mm}^{2}\right)\end{array}$ & $\begin{array}{l}\text { Elongation } \\
\text {-at-break } \\
(\mathrm{mm})\end{array}$ & $\begin{array}{l}\text { Tenacity } \\
\text { strength } \\
\left(\mathrm{N} / \mathrm{mm}^{2}\right)\end{array}$ & $\begin{array}{l}\text { Elongation } \\
\text {-at-break } \\
(\mathrm{mm})\end{array}$ & $\begin{array}{l}\text { Tenacity } \\
\text { strength } \\
\left(\mathrm{N} / \mathrm{mm}^{2}\right)\end{array}$ & $\begin{array}{l}\text { Elongation } \\
\text {-at-break } \\
(\mathrm{mm})\end{array}$ \\
\hline 0 & 44.0 & 0.52 & 49.3 & 0.58 & 24.1 & 0.37 \\
\hline 5 & 40.5 & 0.50 & 44.0 & 0.57 & 17.2 & 0.25 \\
\hline 7 & 34.3 & 0.42 & 38.4 & 0.56 & 15.3 & 0.20 \\
\hline 9 & 30.7 & 0.25 & 32.9 & 0.30 & 11.9 & 0.18 \\
\hline 10 & 29.4 & 0.22 & 26.2 & 0.27 & 10.0 & 0.17 \\
\hline 11 & 20.5 & 0.20 & 21.9 & 0.24 & 9.2 & 0.16 \\
\hline 12 & 20.0 & 0.18 & 18.9 & 0.20 & 8.5 & 0.15 \\
\hline
\end{tabular}

\subsection{Atomic Force Microscopy}

As theaforementioned results showed the increase in thedyeabilityof the copolymers with the increase of diallylamine comonomer content, it was logic to examine the surface of the copolymer films. The examination of the surface of AN-DAGA film (sample 6) $(55: 45) \%$ by atomic force microscope which showed that the film exhibited high roughness (Fig. 9B). This roughness of the surface increased the dyeability of the AN-DAGA copolymer as compared to the smooth PAN film (Fig. 9A).

\subsection{Mechanical Properties}

Table 4 and 5 show that the tensile strength and young's modulus at break of the copolymers' films. All copolymers films possess lower Young's modulus and tensile strength various than PAN film. While, the dyed copolymer films possess higher tenacity and elongation at break as compared to polyacrylonitrile Table 6. It was also found that the improvement in the mechanical properties increases with the increase in the diallylamine salt comonomer content. This means that the copolymerization of acrylonitrile with diallylamine salts gave the copolymer its extra strength.

\subsection{Effect of (UV) Radiation on the Mechanical Properties of AN/Diallylamine Salts}

The dyed copolymer films were kept under prolong exposure to a UV lamp with short wave length $(\lambda=250$ $\mathrm{nm})$ in air to study the effect of UV radiation on the tenacity and elongation at break of their films as compared to PAN film.

It was found that the loss in tenacity and elongationat-break of the copolymer films decreased with the increase in exposure time to UV lamp in air, but still these decreases was less remarkable as compared to that in the case of the PAN film.
Therefore, the copolymerization of acrylonitrile with diallylaminesalts had improved the mechanical properties before and after the photo oxidation as compared to PAN.

\section{CONCLUSION}

Acrylonitrile has been copolymerized with various ratios of diallylamine salts to improve the dyeability of the obtained copolymers as compared to PAN homopolymer.

The dyeability of acrylonitrile-diallylamine acetate (AN-DAA acetate) and acrylonitrile-diallylguanidine acetate (AN-DAGA) copolymers have been studied with both conventional and ultrasonic methods. The results revealed that the dyeing process was highly improved in using the ultrasonic method as compared to the conventional method. This is attributed to the extra vibration and agitation conferred on the dyeing system upon using the ultrasonic method.

The examination of the surface of AN-DAGA film (sample 6) (55:45)\% by atomic force microscope showed that the film exhibited high roughness. This roughness of the surface increased the amount of the dye molecules diffused through the AN-DAGA copolymer matrix and thus increased its dyeability as compared to the smooth PAN film.

The dyed copolymers films were found to films possess higher tenacity and elongation at break as compared to polyacrylonitrile.

\section{REFERENCES}

Abdel-Naby, A.S., 2011. Coplymerization of acrylonitrile with $\mathrm{N}$-(substituted phenyl) itaconamide. J. Applied Polymer Sci., 121: 169-175. DOI: 10.1002/app.33507 
Abdel-Naby, A.S. and S.A. Aboubshait, 2013. Cellulose acetate blends with acrylonitrile/N-phenyl maleimide copolymers morphological and thermal properties. Thermal Anal. Calorimetry. DOI: 10.1007/s10973-013-3153-9

Abdel-Naby, A.S. and S.N. Al-Harthi, 2013. Copolymerization of acrylonitrile with diallylamine salts (under publication).

Abdel-Naby, A.S., 2012. Ultrasound assisted copolymerization of acrylonitrile with N-amino phenyl maleimides and $\mathrm{N}$-amino phenyl 2,3 dimethyl maleimides. Ultrasonic Sonochemistry, 19: 1180-1185. DOI: 10.1016/j.ultsonch.2012.04.004

Bahrami, S.H., P. Bajaj and K. Sen, 2003. Thermal behaviour of acrylonitrile carboxylic acid copolymers. J. Appli. Polym. Sci., 88: 685-698. DOI: 10.1002/app.11637

Boguslavsky, L., S. Baruch and S. Margel, 2005. Synthesis and characterization of polyacrylonitrile nanoparticles by dispersion/emulsion polymerization process. J. Colloid Interface Sci., 289: 71-85. DOI: 10.1016/j.jcis.2005.03.063

Kamel, M.M., H.M. Helmy, H.M. Mashaly and H.H. Kafafy, 2010. Ultrasonic assisted dyeing: Dyeing of acrylic fabrics C.I. Astrazon Basic Red 5BL 200\%. Ultrasonics Sonochemistry, 17: 92-92. DOI: 10.1016/j.ultsonch.2009.06.001
Khan, G.M., M.D. Saheruzzaman, S.M.A. Razzaque, M.D. Islam and M.D. Alam, 2009. Grafting of acrylonitrile monomer onto bleached okra bast fibre and its textile properties. Ind. J. Fiber. Text. Res., 34: 321-327.

Moghadam, S.S. and S.H. Bahrami, 2005. Copolymerization of acrylonitrile-acrylic acid in DMF-water Mixture. Iranian Polymer J., 14: 10321041.

Sanderson, R.D., 2004. Effect of process variables on the iniation temperature and exothermic heat for the copolymerization of acrylonitrile and methylacrylate. Intr. J. Polym. Mater., 53: 229-229. DOI: 10.1080/00914030490277743

Tsai, J.S. and C.H. Lin, 1990. Polyacrylonitrile precursors by copolymers and additives with itaconic acid. J. Mater. Sci. Lett., 9: 869-871. DOI: 10.1007/BF00722155

Zaikov, G.E., Y.A. Malkanduev, S.Y. Khashirova, A.M. Esmurziev and A.I. Mortynenko et al., 2004. Synthesis and potential radical copolymerization of new monomers based on diallylguanidine. J. Applied Polymer Sci., 91: 439-444. DOI: 10.1002/app.13099

Zhou, H., X. Tang, Y. Dong, L. Zhang, W. Wang and X. Xiong, 2011. Multiwalled carbon nanotube/polacrylonitrile composite fibers prepared by in situ polymerization. J. Applied Polymer Sci., 120: 13851389. DOI: $10.1002 /$ app.33218 